\title{
Size at Birth and Early Childhood Growth in Relation to Maternal Smoking, Parity and Infant Breast-Feeding: Longitudinal Birth Cohort Study and Analysis
}

\author{
KEN K.L. ONG, MICHAEL A. PREECE, PAULINE M. EMMETT, MARION L. AHMED, AND \\ DAVID B. DUNGER FOR THE ALSPAC STUDY TEAM \\ Department of Paediatrics, University of Cambridge, Addenbrookes Hospital, Cambridge, U.K. [K.K.L.O., \\ M.L.A., D.B.D.]; Biochemistry, Endocrinology and Metabolism Unit, Institute of Child Health, London, \\ U.K. [M.A.P.]; Unit of Paediatric and Perinatal Epidemiology, University of Bristol, Bristol, U.K. \\ [P.M.E., the ALSPAC Study Team]
}

\begin{abstract}
ABST
There is remarkably wide variation in rates of infancy growth,
however, its regulation is not well understood. We examined the
relationship between maternal smoking, parity, and breast- or bottle-
feeding to size at birth and childhood growth between 0 and 5 y in a
large representative birth cohort. A total of 1335 normal infants had
weight, length/height, and head circumference measured at birth and on
up to 10 occasions to 5 y old. Multilevel modeling (MLwiN) was used
to analyze longitudinal growth data. Infants of maternal smokers were
symmetrically small at birth ( $p<0.0005)$ compared with infants of
nonsmokers, however, showed complete catch-up growth over the first
12 mo. In contrast, infants of primiparous pregnancies were thin at birth
( $p<0.0005)$, showed dramatic catch-up growth, and were heavier and
taller than infants of nonprimiparous pregnancies from 12 mo onwards.
Breast-fed infants were similar in size at birth than bottle-fed infants, but
grew more slowly during infancy. Among infants who showed
\end{abstract}
Size at birth and rate of growth in infancy are important indicators of infant mortality and morbidity; smaller size being a major risk factor for mortality, particularly due to infectious disease $(1,2)$. More recently, early growth patterns have also been linked to adulthood metabolic and cardiovascular diseases that are exacerbated by excessive weight gain and obesity (3). Both small and large size at birth have been related to increased disease risk $(4,5)$, whereas childhood obesity and adult disease risk may be further programmed by rapid, or "catch-up,"

Received October 13, 2000; accepted September 19, 2001.

Correspondence: D.B. Dunger, M.D., Department of Paediatrics, University of Cambridge, Addenbrookes Hospital Box 116, Cambridge, CB2 2QQ, U.K.; e-mail. dbd25@cam.ac.uk

ALSPAC is supported by the Medical Research Council, the Wellcome Trust, the Department of Health, the Department of the Environment and many others, and is part of the World Health Organization-initiated European Longitudinal Study of Pregnancy and Childhood. K.O. was supported by a Medical Research Council Clinical Training Fellowship.

DOI: 10.1203/01.PDR.0000036602.81878.6D catch-up growth, males caught up more rapidly than females ( $p=$ 0.002 ). In conclusion, early postnatal growth rates are strongly influenced by a drive to compensate for antenatal restraint or enhancement of fetal growth by maternal-uterine factors. The mechanisms that signal catch-up or catch-down growth are unknown but may involve programming of appetite. The importance of nutrition on early childhood growth is emphasized by the marked difference in growth rates between breast- and bottle-fed infants. The sequence of fetal growth restraint and postnatal catch-up growth may predispose to obesity risk in this contemporary population. (Pediatr Res 52: 863-867, 2002)

\section{Abbreviations}

ALSPAC, Avon Longitudinal Study of Parents and Childhood SDS, SD score infancy growth $(6-8)$, however, the mechanisms surrounding these links remain elusive (9).

There is remarkably wide variation in rates of infancy growth (10). Its regulation is not well understood, though it is likely to involve appetite and nutrition, which may be influenced by determinants of fetal growth, as well as being influenced by choice of postnatal feeding practice (11). The effects of maternal smoking and parity on size at birth are well described $(12,13)$, however, their influence on postnatal growth is less clear (14-16).

We therefore examined the relationship of these factors, and also of early breast- or bottle-feeding, to size at birth and childhood growth between 0 and $5 \mathrm{y}$ in a large representative birth cohort, the ALSPAC Children in Focus cohort.

\section{METHODS}

Subjects. Recruitment of the ALSPAC cohort has recently been described (8). Briefly, ALSPAC is a geographically based 
cohort born between April 1991 and December 1992. The Children in Focus subcohort are a 10\% random selection that includes 1335 term (gestation 37-42 wk) singletons who were measured at birth and on up on 10 further occasions until $5 \mathrm{y}$ (at 4, 8, 12, 18, 25, 31, 37, 43, 49 and $61 \mathrm{mo}$ ). Informed consent was obtained from mothers and ethical approval was obtained from the ALSPAC ethical committee and from local ethical committees.

Data collection and auxological measurements. Gestation was estimated using date of last menstrual period and confirmed by antenatal ultrasound reports; in cases of discrepancy, the data were reviewed by a single experienced clinician. Mother's parity and smoking during pregnancy were recorded by questionnaire completed during pregnancy. Maternal height was recorded from obstetric records and paternal height was self-reported by questionnaire completed by mother's partner during pregnancy. Birth weights were noted from hospital records and supine length was measured using a Harpenden neonatometer (Holtain Ltd., Crosswell, Dyfed, Wales, U.K.) soon after birth (median $1 \mathrm{~d}$, range 1-14 d) by the ALSPAC study team. Weight (Seca 724 or 835 scales, Seca Ltd., Birmingham) and standing height (Leicester height measure, Child Growth Foundation) were measured at visits to the research clinics.

Calculations. Sex and age independent SDS were calculated in each subject for all weight and length measurements by comparison with the U.K. 1990 growth reference (17) and also separately using internally derived means and SD for each sex at each age point: SDS = (measurement - population mean)/ population SD. Postnatal catch-up growth was defined as an increase in weight SDS between birth and $2 \mathrm{y}$ of $>0.67$ SDS (8); 0.67 SDS is equivalent to the distance between adjacent centile lines drawn on standard growth curves (i.e. 2nd, 9th, 25th, 50th, 75th, 91st, and 98th centiles); at birth, this corresponded to a difference of $320 \mathrm{~g}$ in weight and $1.4 \mathrm{~cm}$ in length. Ponderal index (weight/length ${ }^{3}$ ) was calculated at birth; this was an appropriate weight-for-length index at birth as this parameter was independent of length.

Analyses. To analyze this large longitudinal data set and take into account subjects with missing measurements, we used a multilevel modeling software (MLwiN ver. 1.0 beta, Institute of Education, London, U.K.) (18). This is a hierarchical regression model, which allows consideration of individual growth curves and their summation by predefined groups. Using the whole data set from birth to $5 \mathrm{y}$, variance in weight or length/height SD scores was modeled against age. To recognize growth data for each child, two levels of hierarchy in the data were used: level 1 consisted of all measurement points, and level 2 consisted of unique codes for each child. Models with the categorical explanatory variables maternal smoking, parity, and breast-/bottle-feeding at 3 mo were built separately, and from these models graphs of the predicted values by age between birth and $5 \mathrm{y}$ were drawn.

The use of separate models to analyze maternal smoking, parity, and breast-/bottle-feeding was chosen for simplicity, and was justified by the absence of association between these factors. There was no association between maternal parity and smoking ( $15 \%$ of primiparous mothers smoked, compared with $16 \%$ of nonprimiparous mothers, $p=0.8$ ); nor was there a significant association between parity and breast-/bottlefeeding ( $44 \%$ of primiparous mothers breast-fed, compared with $48 \%$ of nonprimiparous mothers, $p=0.2$ ). The only significant association seen was between maternal smoking and breast-/bottle-feeding $(9 \%$ of mothers who breast-fed were smokers, compared with $17 \%$ of mothers who bottle-fed, $p<$ $0.0005)$; therefore breast- and bottle-fed infants were compared after excluding maternal smokers. Furthermore, at each age point, cross-sectional multivariate analyses including maternal smoking, parity, and breast-/bottle-feeding together were used to examine independent differences in size and to allow further adjustments for parental heights, using generalized linear models (SPSS v.7.0, SPSS, Chicago, IL, U.S.A.). A $p$ value $<0.05$ was considered to define a statistically significant difference.

\section{RESULTS}

All 1335 children were measured at birth and also on at least one occasion during the first year; 1225 were measured at least twice in the first year. In total, 945 children were measured at $4 \mathrm{mo}, 1231$ at $8 \mathrm{mo}, 1164$ at $12 \mathrm{mo}, 1088$ at $18 \mathrm{mo}, 1049$ at 25 mo, 1053 at $31 \mathrm{mo}, 1003$ at $37 \mathrm{mo}, 999$ at $43 \mathrm{mo}, 963$ at $49 \mathrm{mo}$, and 929 at 61 mo. Multilevel modeling analysis allowed growth data from all 1335 children to be used.

Comparison with the U.K. reference. Expressed as U.K. 1990 SDS, mean length/height remained close to the national average between birth (mean \pm SD: $0.09 \pm 1.01$ SDS) and $5 \mathrm{y}$ $(0.11 \pm 0.94 \mathrm{SDS})$, however weight increased progressively from birth $(-0.01 \pm 1.01 \mathrm{SDS})$ to $5 \mathrm{y}(0.29 \pm 1.00 \mathrm{SDS})$ (Fig. $1)$. This trend toward increasing weight-for-height with age in this cohort has previously been reported (19). To examine within-cohort growth determinants, we calculated internal SDS for weight and height and these have been used in all subsequent analyses.

Maternal smoking. One hundred ninety-nine mothers admitted to smoking during pregnancy, 1100 mothers denied smoking, and no information was available in the remainder. Compared with infants of nonsmokers, at birth, infants of smokers were lighter, shorter, and had smaller head circumferences but were no different in weight-for-height (ponderal index $p=0.7$ ) (Table 1). Over the first year of life these infants

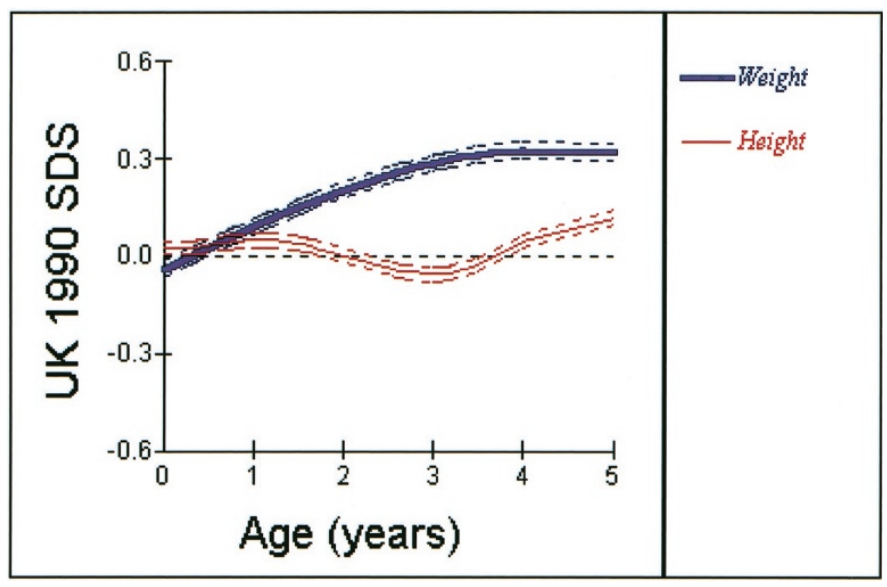

Figure 1. ALSPAC growth curves expressed as 1990 UK Reference weight and length/height SD scores ( $\pm 95 \%$ confidence interval). 
Table 1. Size at birth and gestational age by maternal smoking and parity (means $\pm S D$, adjusted for sex)

\begin{tabular}{|c|c|c|c|c|c|}
\hline & \multicolumn{2}{|c|}{ Maternal smoking } & \multicolumn{3}{|c|}{ Parity } \\
\hline & $\begin{array}{c}\text { Yes } \\
(n=199)\end{array}$ & $\begin{array}{c}\text { No } \\
(n=1100)\end{array}$ & $\begin{array}{l}\text { Primiparous } \\
(n=656)\end{array}$ & $\begin{array}{c}\text { Para 1 } \\
(n=421)\end{array}$ & $\begin{array}{c}\text { Para } 2+ \\
(n=258)\end{array}$ \\
\hline Gestation (wk) & $39.6 \pm 1.1$ & $39.7 \pm 1.2$ & $39.7 \pm 1.2$ & $39.7 \pm 1.1$ & $39.6 \pm 1.2$ \\
\hline Weight (g) & $3305 \pm 463 *$ & $3524 \pm 481$ & $3375 \pm 450^{*}$ & $3574 \pm 475$ & $3640 \pm 511$ \\
\hline Length $(\mathrm{cm})$ & $49.9 \pm 1.9 *$ & $51.0 \pm 1.9$ & $50.6 \pm 1.9^{*}$ & $51.0 \pm 2.0$ & $51.2 \pm 2.0$ \\
\hline Head circumference $(\mathrm{cm})$ & $34.5 \pm 1.3 *$ & $35.0 \pm 1.2$ & $34.8 \pm 1.2^{*}$ & $35.1 \pm 1.3$ & $35.2 \pm 1.2$ \\
\hline Ponderal index $\left(\mathrm{kg} / \mathrm{m}^{3}\right)$ & $26.4 \pm 2.2$ & $26.5 \pm 2.2$ & $25.9 \pm 2.1 *$ & $27.0 \pm 2.1$ & $27.1 \pm 2.4$ \\
\hline
\end{tabular}

* ANOVA $p<0.0005$.

Para 1, one infant delivered previous to this pregnancy; Para $2+$, two or more infants delivered previously.

showed catch-up growth (Fig. 2), and by 12 mo there was no difference in weight $(p=0.9)$, length $(p=0.2)$ or head circumference $(p=0.2)$ between the two groups. The remaining small deficit in height from 12 mo onward in children of smokers, apparent in Figure 2, did not reach statistical significance at any age on cross-sectional analyses.

Parity. Maternal parity had a large influence on size at birth. Infants of primiparous pregnancies were lighter, shorter, had smaller head circumferences and were also thinner (lower
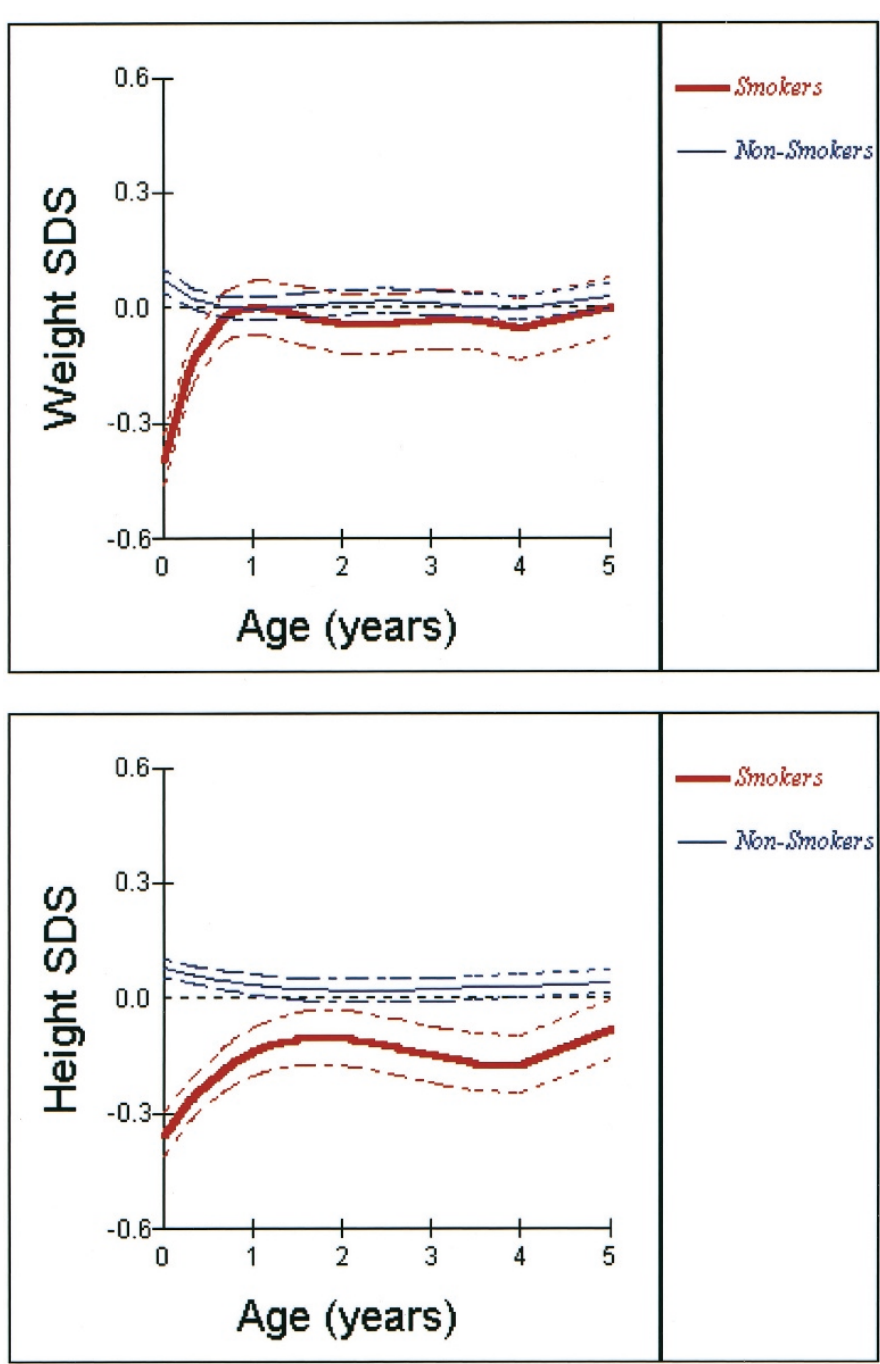

Figure 2. Internally derived SD scores $( \pm 1$ SEM) for weight and height grouped by maternal smoking in pregnancy. ponderal index) at birth compared with other infants (Table 1). During the first year of life, infants of primiparous mothers showed rapid catch-up growth in weight and length, overshooting other infants and they were significantly heavier and longer from 12 mo onward (Fig. 3). Their height advantage persisted after further adjustment for parental heights. Catch-up in head circumference was less rapid and there was no significant difference in head circumference by parity from 8 mo onward (data not shown).
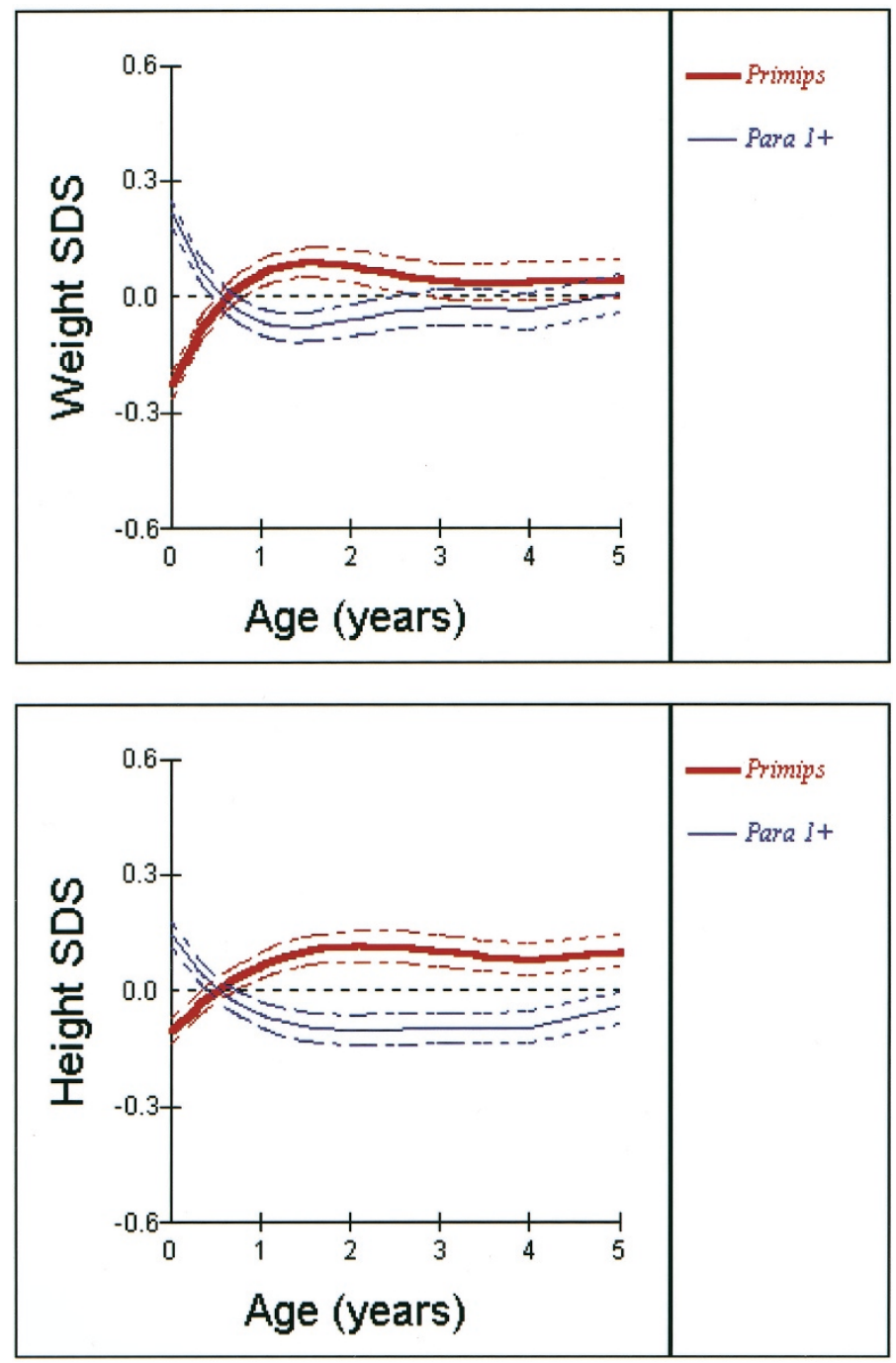

Figure 3. Internally derived SD scores ( \pm 1 SEM) for weight and height grouped by maternal parity. 
Breast-/bottle-feeding. Of the mothers who denied smoking in pregnancy, 425 reported they were still breast-feeding their infants at 3 mo of age and 440 were bottle-feeding. There was no difference in size at birth between infants who were breastor bottle-fed. However, there was a marked divergence in growth during infancy, as breast-fed children showed slower weight and length gain than bottle-fed children (Fig. 4). The difference in weights between these groups was prolonged and was still significant at $31 \mathrm{mo}$ of age $(p=0.02)$. Mothers who chose to breast-feed had significantly higher educational qualifications (58\% had A-levels or university degrees) than mothers who bottle-fed $\left(28 \%, \chi^{2}\right.$ test: $\left.p<0.0005\right)$, however mother's educational achievement did not itself predict weight at birth $(p=0.99), 2 \mathrm{y}(p=0.7)$, or $5 \mathrm{y}(p=0.8)$. No difference in head circumference was seen at any age between breast- and bottle-fed infants.

Sex influence on catch-up growth. The numbers of infants showing catch-up growth were similar in males $(142 / 569$, $25 \%$ ) and females $(139 / 480,29 \%)$, however catch-up males showed a faster initial rate of gain in weight SDS $(2.95 \pm 0.08$ $\mathrm{SDS} / \mathrm{y})$ than females $(2.69 \pm 0.11 \mathrm{SDS} / \mathrm{y}, p=0.002)$.
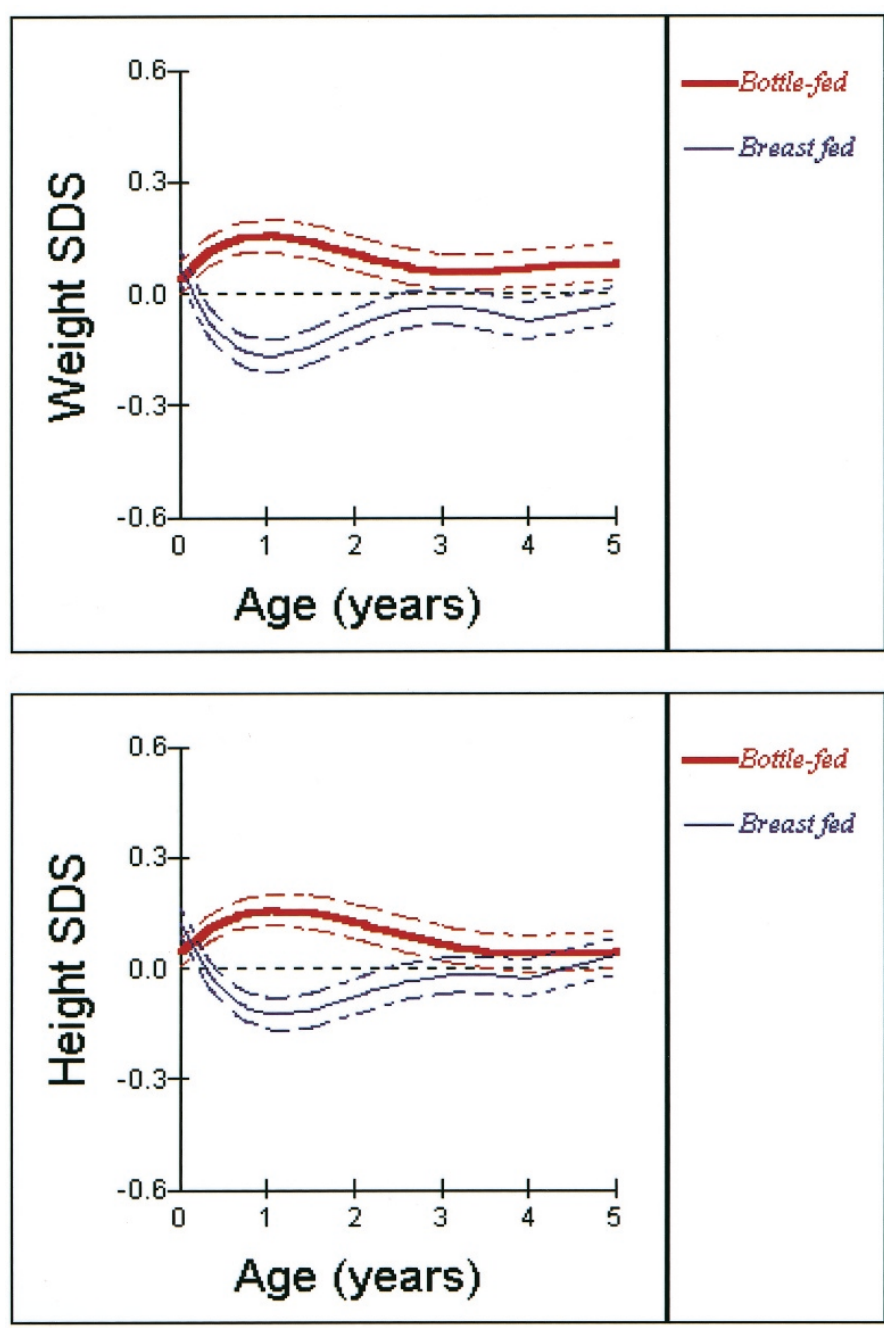

Figure 4. Internally derived SD scores ( \pm 1 SEM) for weight and height grouped by breast- or bottle-feeding.

\section{DISCUSSION}

Using longitudinal analysis of growth data from a large prospective birth cohort, we observed marked and prolonged effects of maternal smoking, parity and infant breast- or bottlefeeding on early childhood growth rates.

Multilevel modeling allows analysis of longitudinal or repeated measures data sets where individuals may have missing measurements on one or more occasions (18). A limitation in using polynomial functions in the fitting of these growth curves, particularly with the lower frequency of measurements with increasing age, was a tendency to exaggerate inflections, possibly resulting in an artificial "meandering" in the growth curves between 3 and $5 \mathrm{y}$. The robustness of the model in the first $3 \mathrm{y}$ of life underlines the marked effects of antenatal and early infancy factors on growth rates in early childhood.

Our data confirm reports of the fetal growth-inhibiting effects of maternal smoking in pregnancy $(12,13)$. The symmetrical reduction in size at birth in infants of smoking mothers suggests that this growth inhibition was present from early fetal development. Earlier and smaller studies have debated whether any size deficit persists into childhood $(14,15,20)$. In our study, infants of smoking mothers showed complete compensatory postnatal catch-up growth in weight, and there was no significant remaining height deficit compared with other infants, however, it is still possible that deficits in bone mineral density and susceptibility to respiratory disease persist $(14,20)$.

Infants of primiparous pregnancies were smaller and thinner at birth but showed dramatic catch-up in weight and length that overcompensated for their initial size deficit and resulted in larger childhood size, even allowing for their parents size. Fetal growth restraint with relative catch-up growth in first pregnancies, and corresponding catch-down growth in infants of high parity, have been described in rural Gambian infants, where it was suggested that availability of postnatal nutrition may be affected by family size (16). In our contemporary, relatively affluent birth cohort (21), the marked variations in postnatal growth even with small increases in parity suggest that a more intrinsic process may be involved.

The mechanisms that signal and regulate postnatal catch-up growth are unknown, however, our current data support the hypothesis that postnatal growth rates are influenced by maternal-uterine factors during antenatal life. Although it is possible that parenting behaviors may differ substantially between primiparous and nonprimiparous mothers, infant nutrition is also largely dependent on appetite. We have previously shown that catch-up growth was predicted by low leptin levels at birth (22). Leptin inhibits appetite and weight gain in humans (23, 24) and these findings support the observation that variation in infancy growth rates may be to some extent mediated through differing preset levels of satiety (11). Thus, in affluent societies where nutrition is plentiful, lower leptin levels leading to increased appetite may explain the excessive postnatal growth seen in thin, in utero restrained infants of primiparous pregnancies.

The importance of nutrition on early childhood growth rates is further emphasized by the marked differences in growth rates between infants who were breast- or bottle-fed at 3 mo. The 
lack of difference in size at birth excludes any initial size-based selection bias in choice of feeding. Bottle-fed infants have higher total energy and protein intake than breast-fed infants (25), and this may stimulate increased insulin secretion (26). We observed that the growth-limiting effects of breast-feeding continued well beyond infancy, and this is consistent with recent data describing protective effects of breast-feeding against obesity risk in later childhood (27). Mothers who breast-fed had higher educational achievements than mothers who bottle-fed. Although maternal education itself was not related to size at birth or postnatal growth, it is possible that decision to breast-feed was related to other maternal behaviors or choices in offspring feeding. Alternatively, early breast- or other feeding behaviors may directly influence later appetite regulation (28). This may possibly be mediated through variations in leptin sensitivity, as recently shown in rodent studies (29).

Lastly, catch-up growth was more rapid and accomplished sooner in males than in females. This could reflect the anabolic effects of early infancy sex hormone production in males $(30$, 31). It is also possible that nutrition-driven postnatal catch-up growth could be modified by other genetic determinants of hormone secretion or metabolism in the infant, such as polymorphisms in the estrogen receptor (32) or insulin genes (33, 34).

In conclusion, these data suggest that postnatal growth rates are strongly influenced by a drive to compensate for antenatal restraint or enhancement of fetal growth by maternal-uterine factors. The sequence of fetal growth restraint and postnatal catch-up growth may predispose to obesity risk in this contemporary population $(8)$.

Acknowledgments. The authors thank all the children and parents who took part and the midwives for their co-operation and help in recruitment. The whole ALSPAC study team comprises interviewers, computer technicians, laboratory technicians, clerical workers, research scientists, volunteers, managers, and also the staff of the Children in Focus research clinics.

\section{REFERENCES}

1. Forssas E, Gissler M, Sihvonen M, Hemminki E 1999 Maternal predictors of perinata mortality: the role of birthweight. Int J Epidemiol 28:475-478

2. Ashworth A 1998 Effects of intrauterine growth retardation on mortality and morbidity in infants and young children. Eur J Clin Nutr 52(suppl 1):S34-S41

3. O'Brien PMS, Wheeler T, Barker DJP 1999 Fetal programming: influences on development and disease in later life. Proceedings of the 36th RCOG Study Group. RCOG Press, London, pp 1-483

4. McCance DR, Pettitt DJ, Hanson RL, Jacobsson LT, Knowler WC, Bennett PH 1994 Birth weight and non-insulin dependent diabetes: thrifty genotype, thrifty phenotype, or surviving small baby genotype? BMJ 308:942-945

5. Stern MP, Bartley M, Duggirala R, Bradshaw B 2000 Birth weight and the metabolic syndrome: thrifty phenotype or thrifty genotype? Diabetes Metab Res Rev 16:88-93

6. Crowther NJ, Cameron N, Trusler J, Gray IP 1998 Association between poor glucose tolerance and rapid post natal weight gain in seven-year-old children. Diabetologia 41:1163-1167

7. Eriksson JG, Forsen T, Tuomilehto J, Winter PD, Osmond C, Barker DJ 1999 Catch-up growth in childhood and death from coronary heart disease: longitudinal study. BMJ 318:427-431
8. Ong KK, Ahmed ML, Emmett PM, Preece MA, Dunger DB, the ALSPAC Study Team 2000 Association between postnatal catch-up growth and obesity in childhood: prospective cohort study. BMJ 320:967-971

9. Lucas A, Fewtrell MS, Cole TJ 1999 Fetal origins of adult disease - the hypothesis revisited. BMJ 319:245-249

10. Tanner JM 1986 Growth as a target-seeking function: catch-up and catch-down growth in man. In: Falkner F (ed) Human Growth; A Comprehensive Treatise, 2nd Ed. Plenum Press, New York, pp 167-179

11. Ounsted M, Sleigh G 1975 The infant's self-regulation of food intake and weight gain. Difference in metabolic balance after growth constraint or acceleration in utero. Lancet 1:1393-1397

12. Davies DP, Abernethy M 1976 Cigarette smoking in pregnancy: associations with maternal weight gain and fetal growth. Lancet 1:385-387

13. Sexton M, Hebel JR 1984 A clinical trial of change in maternal smoking and its effect on birth weight. JAMA 251:911-915

14. Jones G, Riley M, Dwyer T 1999 Maternal smoking during pregnancy, growth, and bone mass in prepubertal children. J Bone Miner Res 14:146-151

15. Russell CS, Taylor R, Law CE 1968 Smoking in pregnancy, maternal blood pressure, pregnancy outcome, baby weight and growth, and other related factors. A prospective study. Br J Prev Soc Med 22:119-126

16. Prentice A, Cole TJ, Whitehead RG 1987 Impaired growth in infants born to mothers of very high parity. Hum Nutr Clin Nutr 41:319-325

17. Freeman JV, Cole TJ, Chinn S, Jones PR, White EM, Preece MA 1995 Cross sectional stature and weight reference curves for the UK, 1990. Arch Dis Child 73:17-24

18. Goldstein H, Healy MJ, Rasbash J 1994 Multilevel time series models with applications to repeated measures data. Stat Med 13:1643-1655

19. Reilly JJ, Dorosty AR, Emmett PM 1999 Prevalence of overweight and obesity in British children: cohort study. BMJ 319:1039

20. Schulte Hobein B, Schwartz Bickenbach D, Abt S, Plum C, Nau H 1992 Cigarette smoke exposure and development of infants throughout the first year of life: influence of passive smoking and nursing on cotinine levels in breast milk and infant's urine. Acta Paediatr 81:550-557

21. Rogers I, Emmett P 1998 Diet during pregnancy in a population of pregnant women in South West England. ALSPAC Study Team. Avon Longitudinal Study of Pregnancy and Childhood. Eur J Clin Nutr 52:246-250

22. Ong KK, Ahmed ML, Sherriff A, Woods KA, Watts A, Golding J, the ALSPAC Study Team, Dunger DB 1999 Cord blood leptin is associated with size at birth and predicts infancy weight gain in humans. J Clin Endocrinol Metab 84:1145-1148

23. Farooqi IS, Jebb SA, Langmack G, Lawrence E, Cheetham CH, Prentice AM, Hughes IA, McCamish MA, O'Rahilly S 1999 Effects of recombinant leptin therapy in a child with congenital leptin deficiency. N Engl J Med 341:879-884

24. Heymsfield SB, Greenberg AS, Fujioka K, Dixon RM, Kushner R, Hunt T, Lubina JA, Patane J, Self B, Hunt P, McCamish M 1999 Recombinant leptin for weight loss in obese and lean adults: a randomized, controlled, dose-escalation trial. JAMA 282: $1568-1575$

25. Heinig MJ, Nommsen LA, Peerson JM, Lonnerdal B, Dewey KG 1993 Energy and protein intakes of breast-fed and formula-fed infants during the first year of life and their association with growth velocity: the DARLING Study. Am J Clin Nutr 58:152-161

26. Lucas A, Boyes S, Bloom SR, Aynsley Green A 1981 Metabolic and endocrine responses to a milk feed in six-day-old term infants: differences between breast and cow's milk formula feeding. Acta Paediatr Scand 70:195-200

27. von Kries R, Koletzko B, Sauerwald T, von Mutius E, Barnert D, Grunert V, von Voss H 1999 Breast feeding and obesity: cross sectional study. BMJ 319:147-150

28. Heinig MJ, Nommsen LA, Peerson JM, Lonnerdal B, Dewey KG 1993 Intake and growth of breast-fed and formula-fed infants in relation to the timing of introduction of complementary foods: the DARLING study. Acta Paediatr 82:999-1006

29. Widdowson PS, Upton R, Buckingham R, Arch J, Williams G 1997 Inhibition of food response to intracerebroventricular injection of leptin is attenuated in rats with diet-induced obesity. Diabetes 46:1782-1785

30. Forest MG, Sizonenko PC, Cathiard AM, Bertrand J 1974 Hypophyso-gonadal function in humans during the first year of life. 1. Evidence for testicular activity in early infancy. J Clin Invest 53:819-828

31. Winter JS, Hughes IA, Reyes FI, Faiman C 1976 Pituitary-gonadal relations in infancy: 2. Patterns of serum gonadal steroid concentrations in man from birth to two years of age. J Clin Endocrinol Metab 42:679-686

32. Suarez F, Rossignol C, Garabedian M 1998 Interactive effect of estradiol and vitamin D receptor gene polymorphisms as a possible determinant of growth in male and female infants. J Clin Endocrinol Metab 83:3563-3568

33. Ong KK, Golding J, Todd JA, Dunger DB 1999 Genetic influences on fetal growth In: O'Brien PMS, Wheeler T, Barker DJP (eds) Fetal Programming: Influences on Development and Disease in Later Life. Proceedings of the 36th RCOG study group. RCOG Press, London, pp 85-96

34. Le Stunff C, Fallin D, Schork NJ, Bougneres P 2000 The insulin gene VNTR is associated with fasting insulin levels and development of juvenile obesity. Nat Genet $26: 444-446$ 